
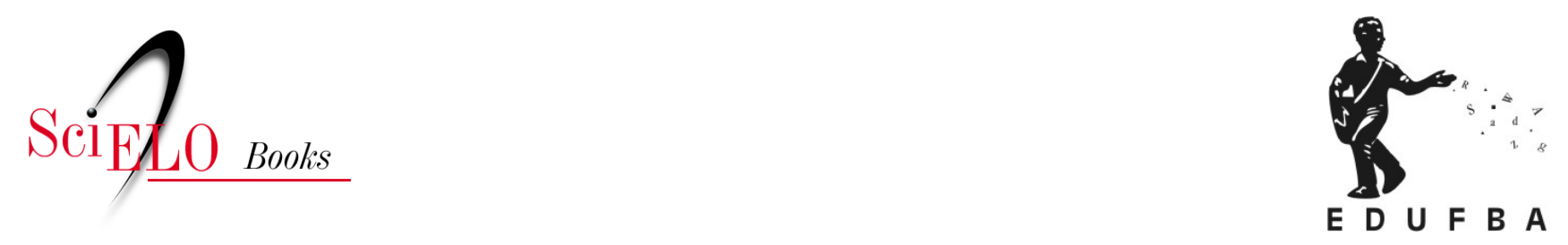

\title{
Psicologia e interfaces pedagógicas Processo ensino-aprendizagem do primeiro período de Engenharia da Univasf: metodologia de ensino e relação professor-aluno
}

\author{
Geida Maria Cavalcanti de Sousa \\ Sávio Silveira de Queiroz
}

\section{SciELO Books / SciELO Livros / SciELO Libros}

SOUSA, G.M.C., and QUEIROZ, S.S. Processo ensino-aprendizagem do primeiro período de Engenharia da Univasf: metodologia de ensino e relação professor-aluno. In: SANTIAGO, A.M.S., and FONSÊCA, A.L.B., comp. Psicologia e suas interfaces: estudos interdisciplinares [online]. Salvador: EDUFBA, 2016, pp. 157-184. ISBN 978-85-232-2007-5.

https://doi.org/10.7476/9788523220075.0007.

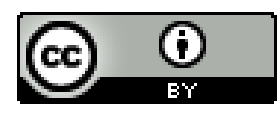

All the contents of this work, except where otherwise noted, is licensed under a Creative Commons Attribution 4.0 International license.

Todo o conteúdo deste trabalho, exceto quando houver ressalva, é publicado sob a licença Creative Commons Atribição 4.0. 


\section{PSICOLOGIA E INTERFACES PEDAGÓGICAS}




\section{Processo ensino-aprendizagem do primeiro período de Engenharia da Univasf: metodologia de ensino e relação professor-aluno}

Geida Maria Cavalcanti de Sousa, Sávio Silveira de Queiroz

Introdução

Os dados da pesquisa de Passos e colaboradores (2007) indicaram elevados níveis de reprovação nos cursos de Engenharia da Universidade Federal do Vale do São Francisco (Univasf), nas áreas de Matemática, Física, Química e Estatística, tendo 81,6\% dos alunos, no mínimo, uma reprovação. Esse contexto foi uma das razões para refletir o processo ensino-aprendizagem nos aspectos da metodologia de ensino e da relação professor-aluno nas disciplinas básicas do primeiro período nos cursos de Engenharia da Univasf, objetivo desta pesquisa.

O motivo da escolha das três disciplinas básicas, Física, Cálculo e Geometria Analítica, está orientada nos estudos de Ramos e cola- 
boradores (2008), que sinalizam uma concentração de reprovação nessas disciplinas e por estarem em todos os primeiros períodos de Engenharia dessa instituição.

Em estudos anteriores (RIBEIRO et al., 2011; SOUSA et al., 2011), os dados evidenciaram os seguintes fatores como interferentes no desempenho acadêmico (associados a outros): a ausência da base do ensino médio, a relação professor-aluno, a metodologia de ensino, a comunicação, a não contextualização dos conteúdos e o processo de avaliação. A metodologia de ensino é um dos eixos do trabalho que segue.

Belli e Bitencourt (2006) colocam que a garantia de acesso e da permanência passa por questões político-pedagógicas, pois o debate deve ser sobre a qualificação pedagógica, que não significa apenas titulação. O professor engenheiro precisa se qualificar pedagogicamente para poder contribuir na permanência, em seus quadros institucionais, daquele aluno que ingressou nesse ensino. A formação desse professor tem o método cartesiano na sua essência, “[...] por esta razão o professor engenheiro é tão rigoroso no seu modelo avaliativo, pois o método utilizado é cheio de rigores e regras que no seu estado perfeito busca a complexidade humana”. (BELLI; BITENCOURT, 2006, p. 21)

O importante não é apenas o domínio do saber. O bom professor provoca intelectualmente seus alunos, problematiza o conteúdo, vivencia situações que incentivam o estudante a participar do percurso da aula, estabelecendo-se um real processo ensino-aprendizagem. (LODER, 2005)

Os textos que seguem contemplam a fundamentação teórica, os procedimentos metodológicos e os resultados agrupados conforme as categorias de análise, constituídas pelos aspectos "processo ensino-aprendizagem e desenvolvimento cognitivo dos estudantes", abordando metodologia de ensino e aprendizagem, linguagem e relação professor-aluno. 


\section{Revisão da literatura}

“Aprender a aprender é um processo em que o próprio sujeito mobiliza suas capacidades cognitivas e afetivas para compreender, controlar e decidir sua aprendizagem”. (ROMANOWSKI, 2006, p. 102) Uma pesquisa feita com os professores da educação básica e da educação superior sobre o que era preciso para realizar a aprendizagem indicou: "necessário conhecer os alunos" e "saber as dificuldades que apresentam”. Os docentes expressaram que os alunos são capazes de compreender informações, de executar experiências e de solucionar questões, mas não elaboram hipóteses, não conseguem explicar os raciocínios usados, nem expressar o que conhecem e o que não conhecem, nem tampouco regulam suas aprendizagens. (ROMANOWSKI, 2006)

Assim, para a aprendizagem acontecer, é preciso que o aluno seja o centro desse processo e que o ensino seja contextualizado. A prática docente para uma aprendizagem interativa coloca o projeto pedagógico em movimento, em aspectos tais como: o planejamento, o saber, a metodologia, a avaliação, o interesse e o envolvimento dos estudantes. A dinâmica da aprendizagem interativa traz a experiência como ponto de partida. A observação e a reflexão sobre os acontecimentos são acentuados, o conhecimento é construído e as leituras e as relações existentes são ampliadas. (ROMANOWSKI, 2006)

A comunicação na aprendizagem acontece por intermédio das experiências que auxiliam os professores a interagir com os alunos, enquanto trabalham com o saber, constituído pelas diversas linguagens usadas na aula: gestos, expressões faciais, olhares e silêncios.

É significante destacar a importância da relação e da comunicação estabelecida entre professor e aluno para o sucesso do estudante no seu aprendizado. Há uma dificuldade nessa comunicação, uns entregam notas e não discutem a resolução das questões, evitam conversar sobre isso com o discente. É preciso que o professor dialogue com seu aluno, de forma a ter acesso, efetivamente, ao seu processo de aprendizado. Isso é reafirmado por Freire (1992, p. 118): 
Não há diálogo no espontaneísmo como no todo-poderosismo do professor ou da professora [...]. O diálogo, na verdade, não pode ser responsabilizado pelo uso distorcido que dele se faça. Por sua pura imitação ou por sua caricatura. O diálogo não pode converter-se num 'bate-papo' desobrigado que marche ao gosto do acaso entre professor ou professora e educandos.

Além disso, os reflexos das dificuldades, durante a educação básica, constituem processos que impedem tal comunicação no momento de avaliação. Vários aspectos são refletidos na compreensão desse fenômeno. Chizzotti (2001) considera que a metodologia de ensino na academia deve ser entendida como "metodologia da educação superior”, posto que, no nível superior, além da pesquisa e da extensão, há também a educação. É preciso que se pense numa metodologia de ensino acadêmica realmente comprometida com a educação. Faz-se também necessário que se investiguem as abordagens teóricas que embasam as práticas didático-pedagógicas desses docentes, para que se compreendam as estratégias e objetivos construídos para o ensino. O ensino superior precisa se apoiar na pesquisa, a partir da consideração de que o ensino é uma prática dirigida à formação do conhecimento, bem como o descobrimento do mundo. A pesquisa é uma atividade cotidiana voltada para a ampliação do conhecimento, a qual tem o poder de desenvolver o ensino:

O ensino ganha significado novo quando propicia o prazer da descoberta e a importância do conhecer, quando provoca a observação, mobiliza a curiosidade, move a busca de informações, esclarece dúvidas e orienta as ações, em suma, quando supre as necessidades vitais do discente. (CHIZZOTTI, 2001, p. 106)

As concepções concebidas como estáveis foram ultrapassadas pelo mundo fluente. As conclusões imutáveis permanentes foram superadas por um mundo em movimento, adicionado, constantemente, de novas descobertas com percepções discrepantes, posições conflitantes e atuações divergentes. As demandas sociais exigem que 
cada um busque novas interpretações, visando o alcance da compreensão dos fatos e dos atos, do universo individual e social, no qual cada um está vivendo. (CHIZZOTTI, 2001)

É pela pesquisa que o aluno poderia aprender a problematizar e a questionar tanto o sentido da produção intelectual de sua área quanto a realidade concreta em que se encontra inserido. Assim, num sentido mais amplo do termo, pesquisa tem relação direta com educação. Para se buscar um ensino com pesquisa, é preciso considerar o aluno capaz de construir sua própria experiência de aprendizagem e contar com um professor que saiba trabalhar com a dúvida, com o novo, permitindo que a resposta pronta ceda às questões do aluno, pela capacidade de reconstruir com eles o conhecimento.

Pinto (2002) aborda a falta de oportunidade de aprendizagem para o aluno, diante de resultados insatisfatórios, de retomada do processo por outro caminho, buscando comportamentos e atitudes mais adequados, que lhe permitam atingir os objetivos definidos pelo professor para cada etapa.

\section{Aspectos metodológicos}

Trata-se de uma pesquisa de campo realizada no campus da Univasf, com os primeiros períodos de Engenharia, em Juazeiro-BA, no período de 2009.2 a 2010.1, sendo um estudo de caso.

Os critérios de inclusão na montagem da lista foram alunos do primeiro período de Engenharia, das disciplinas básicas e exatas, que perpassam todos os cursos: Física Básica, Cálculo Integral e Diferencial I e Geometria Analítica. Os critérios de exclusão foram estudantes de outras disciplinas do primeiro período e dos demais períodos ou por terem feito outra graduação. Com relação aos docentes das disciplinas básicas, foram selecionados cinco de uma lista de doze (dois de cada disciplina básica). O critério de inclusão foi que estivessem matriculados há mais de um ano nesse estabelecimento.

Dos 37 estudantes pesquisados, a maioria (26) se concentra na faixa etária entre 18 e 19 anos, sendo 23 do sexo masculino e 14 do 
sexo feminino, oriundos de seis cursos de Engenharia da Univasf (Agrícola e Ambiental, Civil, da Computação, de Produção, Elétrica e Mecânica). Vale ressaltar que a maioria cursou ensino médio em escola particular (28 deles), sete em escola pública e dois em rede pública e particular.

Os cinco professores pesquisados são de uma das áreas básicas (Física, Cálculo, Geometria Analítica), sendo que cada um tem uma das seguintes formações: bacharel em Matemática, bacharel em Física, engenheiro, licenciatura em Matemática e licenciatura em Física. São três com doutorado e dois com mestrado, todos com mais de quatro anos de experiência docente no ensino superior.

Por meio de uma amostragem estratificada - alocação proporcional, das listas com os nomes dos alunos - fez-se um sorteio de 170 nomes, sendo 28 de cada curso. Desse grupo, foram sorteados 37 sujeitos, acrescentados 15 como suplentes, por meio da tabela de dígitos pseudoaleatórios. Dos selecionados, 12 foram aprovados nas disciplinas básicas e 25 , reprovados.

As entrevistas seguiram os roteiros para docentes e discentes, acontecendo ao término do primeiro período e início do segundo período, momento em que os estudantes já tinham concluído algum processo avaliativo na Univasf (ingressantes do segundo período). As entrevistas foram gravadas usando-se aparelhos "mp3" e, em seguida, foram transcritas na íntegra.

O projeto foi aprovado em 11 de novembro de 2009 pelo Comitê de Ética da Associação de Ensino Superior de Caruaru, seguindo-se todos os procedimentos éticos, além da Carta de anuência feita pela instituição, permitindo a pesquisa no campus de Juazeiro-BA, local onde funcionam os cursos de Engenharia. Cada participante assinou um termo de consentimento, autorizando a sua participação na pesquisa e gravação da entrevista, tendo a garantia da sua não identificação (uso de números para cada um), bem como o uso dos dados para fins acadêmicos. As disciplinas também receberam os números 1, 2 e 3, a fim de não identificar os respectivos professores das disciplinas básicas. 
Os dados das entrevistas foram sistematizados em núcleos temáticos, organizados nos aspectos "metodologia de ensino e aprendizagem", "como os discentes aprendem”, "ser um bom professor de disciplinas matemáticas", "influência da língua ou linguagem na aprendizagem para os alunos” e, por último, "a relação professor-aluno e aprendizagem".

\section{Resultados}

Chizzotti (2001) considera que a metodologia de ensino na academia deve ser entendida como "metodologia da educação superior”, posto que, no nível superior, além da pesquisa e da extensão, há também a educação. É preciso que se pense numa metodologia de ensino acadêmica realmente comprometida com a educação.

\section{Metodologia de ensino e aprendizagem}

No que se refere à metodologia de ensino, 18 estudantes $(48,64 \%)$ sinalizaram a sua influência na aprendizagem (Quadro 1).

Quadro 1 - Metodologia de ensino nas disciplinas básicas - entrevistas aplicadas aos estudantes de Engenharia da Univasf, em 2010

\begin{tabular}{|rc|}
\hline METODOLOGIA DE ENSINO \\
\hline Há cobrança do conteúdo de formas distintas, a depender do professor. & 5 \\
Dificuldade do professor em trabalhar o conteúdo em sala. & 12 \\
Falta de explicação e exemplificação no momento da leitura de slides pelo professor. & 2 \\
Na inexistência do diálogo, o aluno fica com medo de perguntar. & 2 \\
\hline
\end{tabular}

Fonte: Elaborado pelos autores.

É preciso conhecer o conteúdo e o modo de ensinar, apesar de não serem suficientes para uma aprendizagem significativa. Assim, "todo professor precisa conhecer mais do que deve ensinar... e deve ensinar somente aquilo que o aluno precisa ou pode aprender”. (LORENZATO, 
2006, p. 6) Um professor universitário, geralmente, não tem formação pedagógica, traz um sólido conhecimento dos conteúdos específicos da sua área acadêmica. A organização do trabalho pedagógico deve ser vista como um compromisso político e uma competência técnica. Para o professor, não basta "saber”, é preciso "saber fazer”. (VILAS BOAS, 2000)

O processo ensino aprendizagem depende da metodologia de ensino, que deve permitir o diálogo, numa relação em que o estudante tenha coragem de perguntar, sentindo-se um sujeito que participa e demonstra vontade de estudar. Disciplinas na área de Matemática exigem explicação, exemplificação e resolução de exercícios. Ao perguntar se a metodologia de ensino interferia na aprendizagem, houve a percepção das mais variadas formas de ensino, dificuldades na metodologia:

Cada professor tem seu estilo de ensinar, por exemplo, tem professor que fala, fala, fala, não escreve... Às vezes, quando você fala muito e não escreve, o aluno não fixa aquilo na cabeça; às vezes, você fala, fala, o aluno passa pelo lado e se torna muito mais fácil você se distrair numa aula em que fala muito e escreve pouco, outros professores falam ao mesmo tempo e escrevem ou você escreve; os professores falam outra língua e não entende ou não quer que você entenda, o bom é que você tem um curso de engenharia e um curso de línguas né, são duas línguas diferentes ao mesmo tempo. (Aluno 19, reprovado)

Há, claro, assim é, influi muito, porque, porque a forma como o professor passa, assim de uma maneira dinâmica, até mesmo a questão da segurança em relação ao professor, sabe? Porque tem professor mesmo que sabe o assunto, mas é muito inseguro, então faz com que o aluno não tá nem aí pra aprender, dorme na sala de aula, não é o meu caso e não tá nem aí, mais assim a forma, por exemplo, slides, têm professor que apenas lê slide na 
sala de aula e não explica é, por exemplo, meu professor da disciplina 1, a gente tem muita dificuldade sabe? Em relação ao entender a linguagem, porque ele nãofala português, cria uma dificuldade grande, porque a gente, ao mesmo tempo que não entende a matéria, não entende o que ele fala, então assim o que a gente pergunta ele... Não tem a força de vontade de tentar explicar, entendeu? A arrogância não deixa. (Aluno 26, aprovado)

Cada professor/disciplina é distinto no aspecto metodológico, verificando as disciplinas 1, 2 e 3, nos quadros 2, 3 e 4, respectivamente:

Quadro 2 - Metodologia de ensino da disciplina 1 - entrevistas aplicadas aos estudantes de Engenharia da Univasf, em 2010

\begin{tabular}{|rr|}
\hline & DISCIPLINA 1 \\
\hline Ironia com relação aos alunos que não sabiam previamente o assunto. & 6 \\
Explicação, revisão e preocupação com o entendimento dos assuntos. & 7 \\
Introduzia o assunto com seus princípios. & 3 \\
Elogio aos veteranos (reprovados anteriormente), & 2 \\
porque eles respondiam as perguntas do professor. & \\
\hline
\end{tabular}

Fonte: Elaborado pelos autores.

Quadro 3 - Metodologia de ensino da disciplina 2 - entrevistas aplicadas aos estudantes de Engenharia da Univasf, em 2010

\begin{tabular}{|rr|}
\hline & DISCIPLINA 2 \\
\hline mas cobrava os assuntos além do nível trabalhado em sala. & 7 \\
Ensinava bem, numa aula dinâmica. & 4 \\
Explicava com exemplos. & 4 \\
Explicava o assunto sem envolver o aluno. & 3 \\
Usava slides, complementando os textos, mas eram insatisfatórios. & 2 \\
Não havia aprendizagem devido a não facilitação & 3 \\
dos recursos no processo de explicação. & \\
\hline
\end{tabular}

Fonte: Elaborado pelos autores. 
Quadro 4 -Metodologia de ensino da disciplina 3 - entrevistas aplicadas aos estudantes de Engenharia da Univasf, em 2010

\begin{tabular}{|rr|}
\hline & DISCIPLINA 3 \\
\hline \multicolumn{3}{|r|}{ Explicava, resolvia exercícios e instigava o estudante a pesquisar. } & 7 \\
Usava a teoria e fórmulas para resolver questões, sem entendimento dos discentes. & 3 \\
Trabalhou numa perspectiva filosófica e histórica, mas não teve êxito. & 2 \\
Questionava pra saber se havia entendimento por meio de exercícios. & 2 \\
\hline
\end{tabular}

Fonte: Elaborado pelos autores.

Como se tratavam de professores distintos entre as mesmas disciplinas, há categorias que se opõem entre si, por exemplo, explicação satisfatória e não desejável, usando slides para leitura de textos, ironia aos alunos, porque não sabiam responder às perguntas do professor, intimidando-os, numa postura do professor "sabe-tudo". Um aspecto que merece destaque é o preconceito, expresso por um professor quando diz (no depoimento) que "mulher não serve para ser engenheira”. Tais categorias se encontram exemplificadas nos depoimentos que seguem.

A disciplina 3 foi a que teve menor índice de reprovação entre as três, apontando menos aspectos negativos na metodologia de ensino em relação às demais.

Algumas situações estabelecem uma reflexão marcante:

Eu acredito porque o professor ele submete muito ao aluno, ele se sente muito, com muito poder dentro da faculdade em relação ao aluno. Então ele acredita que o aluno vem do ensino médio e a obrigação dele já é saber tudo e, pergunta nenhuma que o aluno faça, qualquer pergunta já é motivo de sarcasmo pelo lado do professor. (Aluno 20, reprovado)

[...] ele já falou na sala que mulher não serve pra ser engenheira e, assim, eu fui a única caloura que passei 
direto nele, porque assim, não tinha como ele me reprovar, porque eu tinha tirado 10.0 na prova dele. (Aluno 26, aprovado)

Ah, mais... assim impactante pro psicológico de qualquer pessoa, devido não ao conteúdo né, devido ao método. Ai entra, novamente, a relação entre o método e a aprendizagem. Geralmente, geralmente não, sempre, nas aulas da disciplina 2, o que acontecia era o professor tratar os alunos como se eles fossem máquina, em que você liga e ela liga e que você desliga e ela não desliga e se você ligar, apertar o botão e ela não ligar, você simplesmente dá um murro no quadro, não é. Fala que a metodologia é humilhação em público pra dizer que o erro não está nele. Então eu acho isso totalmente desumano e causa um efeito psicológico muito danoso na mente de quem assiste aula, mesmo que não esteja falando com a própria pessoa. Mas o clima psicológico dentro da sala é completamente ruim. (Aluno 34, aprovado)

Olha! Eu acho que é essencial um professor que saiba explicar bem, porque ajuda bastante o aluno quando ele chega em casa. Porque, se o professor é daqueles que... que explica mas... explica daquela forma que o aluno não consiga compreender bem o que é que ele tá querendo transmitir, às vezes, o aluno tem que chegar em casa pegar um livro pra ler e nem sempre você consegue ter esse dominio assim, ser autodidata, nem todo mundo tem esse dom de ser assim. É um dom que você vai adquirindo com o tempo, mas nem todo mundo tem essa facilidade. Mas, se o professor explica bem, quando você chega em casa, mesmo que você tenha dificuldade em alguma coisa, você consegue retomar o raciocínio do professor, consegue entender o assunto. Então, eu acho que é essencial também ter um bom professor na matéria. (Aluno 36, aprovado) 


\section{Como os discentes aprendem}

Os estudante, ao serem questionados sobre como aprendiam, responderam (Quadro 5):

Quadro 5 - Como o estudante aprendia as disciplinas básicas das engenharias entrevistas aplicadas aos estudantes de Engenharia da Univasf, em 2010

\begin{tabular}{|rrr|}
\hline & APRENDIA AS DISCIPLINAS BÁSICAS \\
\hline Individualmente, em casa, por meio de exercícios e pesquisa. & 7 \\
Coletivamente, por meio de resolução de questões. & 7 \\
Com a explicação do professor, utilizando exercícios e pesquisa. & 10 \\
Individual ou em grupo, resolvendo questões e estudando. & 4 \\
\hline
\end{tabular}

Fonte: Elaborado pelos autores.

O aluno vai construindo seu aprendizado na interação professor-aluno, aluno-aluno, sendo o professor um guia de referência. A ele, cabe orientar esse processo de construção, vivenciando teorias e problematizando o conteúdo por meio de desafios lançados ao discente, cuja aprendizagem deve ser avaliada continuamente. A partir daí, novas alternativas surgem. (LODER, 2005)

Nessa prática, há o estudo diário por meio do uso de livros, pesquisa na internet, resolução de questões, sem dispensar a explicação do professor. O estudo em grupo incentiva a resolução de exercícios, um aluno ajuda o outro a sanar as dúvidas, revisa o que foi dado em sala.

Os trechos mostram as afirmações apontadas:

A gente aprende muito na aula do professor, porque, como eu disse, ele usa esse aprendizado, mas a gente não pode deixar de lado o estudo em casa, certo. Acho que o que o professor dá na sala é $10 \%$ do que você precisa. Eu costumo dizer que $90 \%$ você aprende em casa, aí então vai muito dessa... eu pelo menos, eu... acho que eu aprendo pelo menos $80 \%$ em casa. Aí, eu já estudo antes 
da aula, quando eu chego aqui, o professor... na medida que ele vai explicando, ele vai falando as minhas dificuldades, algumas coisas que eu não entendi, o que eu não entendi, eu pergunto. E assim vai. (Aluno 35, aprovado)

Buscar um aluno que saiba mais na sala, acho que você tem que se dedicar, às vezes, não precisa ser o melhor, ser aquilo tudo, saber estudar em grupo, saber correr atrás do professor quando tiver uma dúvida e ter dúvida, às vezes, o aluno não tem dúvida, dúvida nenhuma, é porque não buscou, mas quando você estuda você vai tirar suas dúvidas, vai atrás do professor, vai atrás de um aluno que saiba mais, vai atrás de uma tutoria, correr atrás. (Aluno 19, aprovado)

Questionou-se ao aluno como o professor pensava que o estudante aprendia. As respostas mais citadas foram: se ele fizer questões, tirar dúvidas, estudar em casa (16), o professor dá o assunto, quanto mais aprofundado e mais difícil, pensa que o aluno tem obrigação de saber tudo, não compreende o lado de cada um (7), outros se preocupam com a aprendizagem do aluno, perguntam, incentivam a procurar ajuda, tutoria, esclarecer dúvidas (2), outros, com explicação, participando da aula (2), seguindo o professor e o livro didático (2). Os depoimentos que seguem reafirmam e apresentam outras informações:

Só que ele esquece que o aluno tem outras matérias, quando ele sai da sala tem outro professor querendo a mesma coisa e esquece que o aluno é um ser humano, $e$ um ser humano ainda 'aborrecente', que além de gostar de brincadeiras, não tem compromisso com o próprio futuro. (Aluno 12, reprovado)

É... Às vezes, o professor até... No momento ali que ele tá dando aula, ele pensa que você já aprendeu o que ele falou. Só que, na verdade, você não aprendeu, você ali 
começou a entender o assunto, mas você não aprendeu. Ai, no momento em que você vai pra casa, que você pega no livro, vai estudar, resolver as questões, ai sim você tá aprendendo. (Aluno 31, aprovado)

Para os docentes, os alunos têm diferentes formas de aprender: uns, por meio de explicação, outros necessitam de atendimento individual, e outros resolvem exercícios junto com o professor. A aprendizagem ocorre por meio do estudo, da leitura, da resolução de exercícios, da explicação do assunto e de revisão. Para isso, o estudante precisa querer, esforçar-se, ter responsabilidade, instigar, provocar o professor, procurar uma complementação do que foi visto na aula. É importante entender as diferenças entre os objetos matemáticos e saber relacioná-los entre si. Os depoimentos que seguem reafirmam o já mencionado:

$E$, entender, entender as diferenças, ter uma clareza dos diferentes objetos matemáticos, por exemplo, o que é uma definição, o que é um teorema, por exemplo, o que é um evento, ter clareza desses diferentes objetos e saber relacioná-los entre si. Eu acho que isso leva a uma boa aprendizagem. É quando o aluno não tem esse entendimento eu acho que a aprendizagem fica comprometida. (Docente 1)

[...] fazer exercícios pro aluno depois, é, estudar, voltar, reler pra entender o que ele não entendeu da outra vez, da parte de matemática e por que ele não entendeu da construção da ligação entre o conhecimento, dos vários conhecimentos que ele não entendeu, que não conseguiu entender isso daí, usar a teoria para as várias situações [...]. (Docente 3) 
Ao solicitar, aos discentes, as sugestões de como os conteúdos matemáticos deveriam ser trabalhados, as respostas foram: explicar claramente e se preocupar com o aluno, esclarecer as dúvidas e ter menos pressa (5), a forma estava satisfatória (5), falar português, explicar de forma mais lenta, detalhar as informações, informar a origem do resultado e esclarecer as dúvidas (2), expor o assunto, fazer exercícios e mostrar aplicação (2).

$\mathrm{Na}$ disciplina 2, poderia ser trabalhada a parte prática (três dimensões, intersecção com plano), com exemplo e algum slide com a forma do objeto, construindo possibilidades de material disponível na internet, além da monitoria. É preciso diálogo, resolução de exercícios, usar uma metodologia que exercite bastante e que não cobre o aprender de uma só vez, além de ter o prazer de ensinar, não demonstrando frustração.

Alguns depoimentos reafirmam as situações apresentadas:

Eu acho que é a questão do professor mesmo, que eu vejo muito aqui, a gente tem mestres, doutores, só que muitos sabem o assunto, mas não sabem passar, não têm a didática, não aprenderam dar aula, sabem o assunto mais não têm... antes do professor entrar na faculdade, devia ter uma capacitação pra dar aula. (Aluno 10, reprovado)

Bom, eu acho que o professor deveria falar outra língua, né? Pra que eu pudesse começar a entender o que ele tava falando, eu acho que ele poderia ser bem mais maleável com relação a dúvidas, no sentido de tirar nossas dúvidas. (Aluno 16, reprovado)

Principalmente de uma forma bem dinâmica, né... eu acho que o que vai motivar o aluno é quando você mostra que aquilo tem um valor e que é aplicável, não é. E muito cuidado, e tá sempre fazendo uma autoanálise do seu método, também é interessante. (Aluno 34, aprovado) 
Deveriam ser trabalhados, como eu falei, né, que vai pro quadro, resolve questão, explica o assunto e explica de um modo, mas, que... Que seja mais simples, que você precisa entender, porque se ficar botando só coisa complicada no quadro e ninguém entender não vai adiantar de nada você resolver questão, tem que ser de um modo que todo mundo entenda, num sei... (Aluno 32, aprovado)

Os professores sugeriram realizar a contextualização dos problemas, usar um computador para mostrar as figuras 3D e desenhos para trabalhar os assuntos, porque facilitam a aprendizagem dos conteúdos matemáticos. Além disso, vale ressaltar a importância dos exemplos levados para aula e a sua forma de escolha, a relação entre os conteúdos, aulas específicas, tais como monitoria e tutoria. Tais sugestões se encontram nos depoimentos que se seguem:

Eu faço um esforço de tentar contextualizar aqui ali, os livros mesmo vou dando as indicações pelos conhecimentos que a gente vai adquirindo e as conversas com os colegas né? A gente vai tentando contextualizar [...] se você tiver trabalhando com um problema, eu acho que a contextualização facilita né? (Docente 5)

Tem dificuldades porque você, às vezes, vai fazer um desenho e o desenho não sai tão perfeito, né, como fica no livro, se você traz o computador e você consegue mostrar pra eles como, por exemplo, você tem uma curva e você gira essa curva em torno de determinado eixo, aí você vai ter uma figura $3 \mathrm{D}$, três dimensões [...]. (Docente 4)

Quanto às atividades matemáticas que envolvem o aluno, na perspectiva do discente, veja o Quadro 6: 
Quadro 6 - Atividades matemáticas que despertaram maior interesse do discente - entrevistas aplicadas aos estudantes de Engenharia da Univasf, em 2010

\begin{tabular}{|rr|}
\hline QUANDO AS ATIVIDADES MATEMÁtICAS SÃO INTERESSANTES \\
\hline Houve uma atividade para nota. & 7 \\
Houve interação, o aluno pergunta e participa. & 7 \\
O professor trabalhou situações que poderiam ser aplicadas. & 3 \\
Despertou a curiosidade, a vontade de aprender. & 4 \\
O professor demonstrou ter domínio do assunto. & 2 \\
\hline
\end{tabular}

Fonte: elaborado pelos autores.

As atividades para nota e interação na aula foram aspectos marcantes que despertaram interesse do educando, seguidos de aplicação de conteúdos, o instigar da curiosidade e domínio do assunto pelo docente.

O depoimento que segue ilustra tais atividades:

Quando o assunto é bom, quando o professor sabe dar aula, porque assim, por exemplo, tem assunto que realmente é muito chato, mas o professor ajuda entender, transforma uma aula dinâmica, brinca, dando exemplos; então, o aluno tá ali interagindo, a disciplina 2 mesmo, o professor dava uma aula bem dinâmica, sabe? A gente aprendia a disciplina 3 também, mas a disciplina 1 não adiantava. (Aluno 26, aprovado)

\section{Ser um bom professor nas disciplinas básicas}

Ao estudante ser indagado sobre o que é um bom professor, as informações se concentraram em (Quadro 7): 
Quadro 7 - Ser um bom professor nas disciplinas básicas - entrevistas aplicadas aos estudantes de Engenharia da Univasf, em 2010

\begin{tabular}{|rr|}
\hline & SER UM BOM PROFESSOR \\
\hline Ser paciente e preocupar-se com o aluno, auxiliando-o. & 19 \\
Ensinar bem. & 23 \\
Ter domínio do conhecimento. & 6 \\
Demonstrar a aplicação dos assuntos e oportunizar atividades para o aluno entender. & 7 \\
Ter uma metodologia interessante e cobrança coerente com o que foi dado em sala. & 5 \\
\hline
\end{tabular}

Fonte: Elaborado pelo autores.

Ser bom professor implica, principalmente, em saber trabalhar o assunto e em ter o domínio do conteúdo, percebendo o discente como um ser "aprendente", envolvendo-o e permitindo a interação.

Os depoimentos que seguem esclarecem as categorias:

Um bom professor nunca será aquele que aprova todo mundo, nem aquele que reprova todo mundo. É aquele que dá a sua aula... que cobra de acordo com o que foi dado, e que uma prova dele não tenha uma questão que nenhum aluno dele não consiga fazer. Eu acho isso ridículo... Se ninguém conseguir fazer uma questão, o problema eu acho que não estaria nos alunos não. Por mais que tenha muito aluno desinteressado, tem aquelas exceções. (Aluno 15, reprovado)

Ser bom professor na área de Cálculo, é primeiro você dominar o conteúdo, depois é você entender que o valor, que as cadeiras são iguais, mas que os alunos não são iguais... Se cada pessoa é diferente da outra, a forma de raciocinar também... tem que compreender que todas as pessoas não vão responder da mesma forma, aquilo que ele está colocando e que ele tem que procurar alternativas de deixar o mais claro possivel, às vezes, de formas diferentes. É muito importante. (Aluno 34, aprovado) 


\section{Influência da língua ou linguagem na aprendizagem para os alunos}

O Quadro 8 retrata a influência da língua ou linguagem na aprendizagem para os alunos:

Quadro 8 - Influência da língua/linguagem na aprendizagem - entrevistas aplicadas aos estudantes de Engenharia da Univasf, em 2010

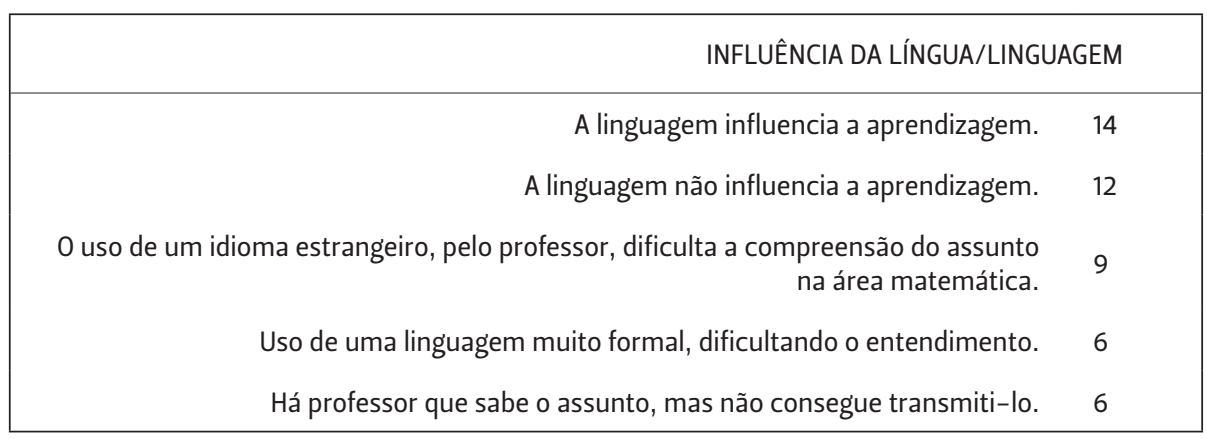

Fonte: elaborado pelos autores.

A metodologia de ensino deve aproximar a Matemática da língua materna, utilizando o uso contextualizado da linguagem. (MENEGAT, 2007) Como isso é possível quando o professor não fala a língua, nesse caso, portuguesa? Como a comunicação se estabelece?

Os estudantes afirmam que, como o aluno não tem coragem de perguntar ao professor que fala outra língua, há uma relação de intimidação. A alternativa encontrada, por ele, foi estudar o assunto previamente, para entender a fala e acompanhar o assunto. Dessa forma, a aprovação é considerada mérito do aluno. Além disso, um professor precisa falar a linguagem do aluno, saber passar o assunto, pois o estudante é jovem e está começando a entender como as coisas funcionam, não dificultando a compreensão de quem está ingressando na universidade. 


\section{A relação professor-aluno e aprendizagem}

A relação professor-aluno apresenta as suas especificidades conforme a disciplina, a depender do professor que a turma teve (Veja Quadro 9).

\section{Quadro 9 - Relação professor-aluno nas disciplinas básicas}

\begin{tabular}{|c|c|}
\hline & $\begin{array}{l}\text { - Havia uma relação conflituosa entre os alunos e professor; } \\
\text { - O professor resolvia exercícios, respondia as perguntas, mas os alunos ainda ficavam com dúvidas; } \\
\text { - Teve um bom relacionamento; } \\
\text { - Alguns dias chegou expressando raiva; outros, brincando; } \\
\text { - Professores estavam sempre disponíveis. }\end{array}$ \\
\hline & $\begin{array}{l}\text { - Professor ironizava os alunos por conta das notas baixas, demonstrava ser superior, a fim de causar } \\
\text { medo, numa relação distante. Sem interação, demonstrava uma má-vontade em tirar dúvidas; } \\
\text { - Demonstrava raiva da turma e dificultava a aprendizagem; } \\
\text { - Não tinha paciência para ensinar e pensava que os alunos já sabiam; } \\
\text { - Professor era mais fechado; } \\
\text { - Relação ótima, professor sabia explicar, tirava as dúvidas, ajudava na resolução } \\
\text { de exercícios. }\end{array}$ \\
\hline Disciplin & $\begin{array}{l}\text { - Era compreensivo e pensava nos alunos; } \\
\text { - Maior contato com o aluno; } \\
\text { - Os alunos não respeitavam o professor, entravam e saíam a todo instante; } \\
\text { - Professores estavam sempre disponíveis. }\end{array}$ \\
\hline
\end{tabular}

Fonte: Elaborado pelos autores.

Sobre a relação professor-aluno, o docente, por meio de elos de afetividade, favorece um intercâmbio entre ele e os estudantes, vivenciando um processo de conquista para despertar o interesse deles, acontecendo o ensino-aprendizagem. O docente necessita da confiança dos discentes, pois, na carência dessa relação afetiva, o ato de educar será incompleto, com inúmeras lacunas e, consequentemente, sem o envolvimento dos estudantes, nenhuma aprendizagem significativa acontecerá. Uma boa relação com o professor gera respeito, a turma participa, interage. Ao contrário, o aluno silencia a sua dúvida. Sobre isso, os relatos reafirmam:

Digamos que esses professores de exatas precisariam fazer uma faculdade de Pedagogia. Porque eles são bons 
em contas, não em lidar com as pessoas, é simples, é o óbvio. Como eu falei, o professor tem que tá um degrau acima e mostrar que... É... Acima das relações interpessoais existe o trabalho aqui a ser feito e... Existem mestres e alunos, certo?! (Aluno 12, reprovado)

[...] aquelas pessoas que não deveriam ser professores e são? Pronto. Primeiro, porque não têm paciência pra ensinar; segundo, ensina pensando que todo mundo já sabe; não é assim. Se você é professor, você tem que ir com convicção, 'eu vou ensinar o que eles não sabem'. Então, se eu vou ensinar o que a outra pessoa não sabe, tem que procurar a melhor maneira para que ela entenda, não pensar da forma se eu sei eles também devem saber, não. (Aluno 2, reprovado)

Assim, eu acho que muitos professores conseguem se relacionar bem com o aluno. Mas a maioria assim... não tem aquela comunicação com os alunos, não conversa com os alunos, não sabe sequer o nome dos alunos... (Aluno 31, aprovado)

Uma grande parte dos alunos declarou que existe influência nessa relação. Outras respostas justificadas foram (Quadro 10):

Quadro 10 - Influência da relação professor-aluno na aprendizagem entrevistas aplicadas aos estudantes de Engenharia da Univasf, em 2010

\begin{tabular}{|c|c|}
\hline \multicolumn{2}{|c|}{ RELAÇÃO PROFESSOR-ALUNO } \\
\hline A boa relação dá mais segurança, favorece ao diálogo e é um estímulo ao estudo. & 8 \\
\hline A distância entre o professor e o aluno faz surgir o medo e a pressão. & 10 \\
\hline $\begin{array}{l}\text { A relação não influencia na aprendizagem, } \\
\text { apesar de os professores não interagirem com os alunos. }\end{array}$ & 3 \\
\hline Quando o aluno responde errado e é repreendido, o aluno passa a ter medo de errar. & 2 \\
\hline $\begin{array}{l}\text { A relação professor-aluno influencia na aprendizagem, } \\
\text { podendo causar desinteresse ao aluno. }\end{array}$ & 24 \\
\hline
\end{tabular}

Fonte: Elaborado pelos autores. 
Outras influências citadas: quando o professor confia no aluno e busca ajudá-lo, há mais disposição para aprender, estudar, avançar, pois uma boa relação professor-aluno permite que o aluno erre como forma de construção, não havendo repreensão. Quando há constrangimento na relação, o aluno se desestimula, desiste de cursar a disciplina, evitando uma reprovação ou conflito futuro. O depoimento que segue aborda a possibilidade de influenciar:

Porque, quando o professor se distancia demais, por exemplo, dos alunos, é... os alunos têm medo, ficam com medo do professor, da pressão que a presença dele exerce. Ai você não se sente à vontade, por exemplo, pra tirar uma dúvida, é... Você fica até... Com receio de... Das avaliações em si, você perde um pouco o interesse por medo. (Aluno 30, aprovado)

Mais da metade dos professores pesquisados reconhece a influência da metodologia no processo ensino-aprendizagem. Segundo eles, se o aluno não entendeu o assunto, o professor precisa adaptá-lo a um contexto que permita a aprendizagem. Além disso, é necessário buscar as razões da não aprendizagem para encontrar alternativas, novas estratégias de ensino. Há uma necessidade de rever e avaliar sempre a metodologia de ensino.

\section{Considerações finais}

Uma grande parte dos alunos pesquisados (24) acredita que a relação professor-aluno influencia na aprendizagem, sendo que apenas três não acreditam nessa possibilidade. Há o sentimento de medo e vergonha por não saber o assunto ou pelo erro cometido, numa relação de distância entre docente e discente, inexistindo o diálogo. Quando o discente pergunta, o professor demonstra impaciência ao ensinar e os conflitos marcam a prática pedagógica. Acrescenta-se a isso uma dificuldade de comunicação, pelo uso de uma língua não dominada pelos alunos. 
Quase a metade dos estudantes reforçou a influência da metodologia de ensino nas disciplinas básicas, abordando dificuldades dos professores: na forma de explicar o assunto, na linguagem utilizada, na avaliação (cobrança além do trabalhado em sala), na relação professor-aluno e na comunicação. Apontaram casos de docentes que ironizavam os alunos quando faziam perguntas, elogiavam os veteranos por saberem mais que os ingressantes, usavam recursos didáticos inadequados para a área de matemática (datashow), discriminavam as mulheres que faziam Engenharia. Destacaram professores que explicavam bem, revisavam os conhecimentos prévios, tiravam as dúvidas, resolviam exercícios em aula.

A maior parte dos professores pesquisados também reconhece a influência da metodologia no processo ensino-aprendizagem, sendo que é preciso adaptar o conteúdo a um contexto que permita a aprendizagem. Eles demonstram uma forte resistência em mudarem seus métodos de ensino, e preferem a acomodação à modificação. Num outro contexto, o aluno passaria a ser o autor da aprendizagem, sendo mais ativo e construtivo, desenvolvendo o pensamento crítico e sendo desafiado intelectualmente, com espírito de colaboração e de iniciativa, como afirmam Silva e Cecílio (2007).

Além disso, os estudantes seriam estimulados a desenvolver a curiosidade e a elaborar seu próprio conhecimento, tendo a interação como eixo central e o professor como mediador, num ambiente dinâmico e ativo, com o uso de ferramentas para orientação, resolução e problematização de questões acadêmicas. Porém, esse quadro é contraditório na fala dos estudantes, que são incentivados ao silêncio (isso nas disciplinas pesquisadas) e as aulas se resumem ao quadro e pincel, normalmente. Há casos do uso do datashow, mas para ler informações referentes ao cálculo, cujas situações demandam resolução de questões e não apenas leitura. É preciso educar para a liberdade e para a autonomia. Para isso, o professor precisa ser:

[...] capaz de se relacionar com uma diversidade de estudantes, de mobilizar seus interesses e motivações e de, com eles, 
construir oportunidades de aprender e de transformar. Isso significa abertura, capacidade de adaptação a experiências diferentes." (SILVA; CECÍLIO, 2007, p. 64)

Os estudantes expressaram que os assuntos da área de Matemática deveriam ser explicados de forma clara e mais lenta, as dúvidas serem esclarecidas, o professor falar a língua portuguesa e resolver exercícios em sala, além de mostrar a sua aplicação e usar uma metodologia interessante, favorecendo, assim, a interação e ter a aprendizagem como meta. Sugeriram a contextualização dos problemas por meio de figuras ou desenhos $3 \mathrm{D}$, que melhor representem os assuntos, e, ainda, exemplos que se relacionem com a aprendizagem dos conceitos matemáticos e incentivo aos programas de tutoria e monitoria.

Algumas contradições são percebidas no processo de formação dos engenheiros. "De um lado, engenheiros que se 'tornam professores' e ensinam o que sabem fazer; de outro, professores que 'ensinam’ o que não fazem na prática.”. (SILVA; CECÍLIO, 2007, p. 64) Uns ensinam em razão da formação e do exercício da profissão, podendo ser sem a intenção da dimensão pedagógica docente; outros "ensinam" a teoria sem articulação com a prática, trazendo dificuldades no processo ensino-aprendizagem e produzindo insatisfações no estudante. É preciso perceber a atuação docente como além da repetição do que se aprendeu na graduação, prática comum entre os professores.

Outra reflexão está no fato de que os discentes não conseguem entender onde vão usar os saberes das disciplinas básicas, consideradas abstratas, que irão auxiliar as disciplinas profissionalizantes, gerando desmotivação e desatenção por parte deles.

É consenso que aprender as disciplinas básicas depende do estudo diário em casa e da resolução de exercícios. De acordo com Menegat (2007), compete ao docente desenvolver atividades que visem à compreensão da Matemática e não apenas ensinar com exercícios resolvidos de maneira mecânica. O estudante precisa ser capaz de aplicar as ferramentas matemáticas e solucionar problemas seme- 
lhantes, que apareçam no percurso da vida, entendendo o real significado das suas ações.

Dessa forma, os objetivos foram atingidos - refletir sobre o processo ensino-aprendizagem e apresentar a metodologia de ensino das disciplinas básicas do primeiro período dos cursos de Engenharia da Univasf e a influência da relação professor-aluno - evidenciando os seguintes fatores como interferentes no desempenho acadêmico (articulados a outros elementos): metodologia de ensino, relação professor-aluno, comunicação, não contextualização dos conteúdos, processo de avaliação e ausência da base do ensino médio.

Frente a isso, pergunta-se: os aspectos psicológicos e pedagógicos afetam o desempenho do estudante de Engenharia? Ambos os grupos pesquisados, aprovados e reprovados, levantam elementos que nos levam a acreditar nessa interferência: carência de formação pedagógica, ausência de recursos adequados, dificuldade de trabalhar os conteúdos, ausência de diálogo, aula sem interação, medo de fazer perguntas, gerando sofrimento psicológico, postura irônica no trato com o aluno (quando comete erros), desprezo aos calouros (ainda "não sabem" o conteúdo), dificuldades na comunicação, além do uso de uma língua estrangeira. Como se explica isso, se trabalhar com números requer interação de assuntos, interdisciplinaridade entre áreas, criatividade, principalmente um nível alto de abstração?

A literatura existente também reafirma isso, a exemplo de vários autores. Grillo (2001) considera a docência como o envolvimento do professor em sua totalidade, em quatro dimensões: pessoal (a maneira de ser se cruza com a forma de ensinar), prática (articula saberes formalizados e da experiência - fazer docente), conhecimento profissional docente (saberes científicos, psicopedagógicos, experiências de prática pedagógica e didáticas específicas) e contextual (realidade contextual no espaço da aula). Pensando assim, essas ponderações instigam uma resposta à questão levantada.

Reproduzir o saber conhecido leva a uma exclusão da curiosidade, do entusiasmo, da descoberta e do esvaziamento de sentido no 
processo de aprendizagem. Amaral e Martínez (2009) refletem a falta de criatividade no processo educativo, lançado no ensino superior, devido ao modelo passivo reprodutivo em atividade. As características subjetivas, presentes no alicerce da expressão criativa da pessoa, não são reconhecidas por parte dos educadores, dificultando o acesso de estratégias que visem à criatividade. "Isso supõe que a aprendizagem depende muito da condição subjetiva de quem aprende e do contexto em que está inserido.” (AMARAL; MARTÍNEZ, 2009, p. 150)

As estratégias pedagógicas são implicadas com as relações sociais estabelecidas, sendo recursos que orientam o professor na elaboração de canais dialógicos, conhecendo as articulações cognição-afeto. "A ideia é a de que a estratégia pedagógica esteja orientada para o sujeito que aprende e não para o conteúdo a ser aprendido.” (TACCA, 2008, p. 48) A resposta do aluno deve ser a ponte para o diálogo, visando à compreensão e aos esclarecimentos para o estudante reelaborar sua aprendizagem.

Assim, deixa-se como reflexão que pensar o processo de aprendizagem exige o diálogo como eixo, objetivando uma construção conjunta de conhecimentos, situação em que o interlocutor esteja aberto nessa relação. Deixa-se a possibilidade de estudar sobre os conteúdos e procedimentos metodológicos utilizados na Matemática, no ensino fundamental e médio, para buscar explicações sobre a ausência de base nos alunos, investigando, também, a forma como os saberes são trabalhados em sala de aula.

\section{Referências}

AMARAL, A. L. N.; MARTíNEZ, A. M. Aprendizagem criativa no ensino superior: a significação da dimensão subjetiva. In: MARTínEZ, A. M.; TACCA, M. C. V. R. (Org.). A complexidade da aprendizagem: destaque ao ensino superior. Campinas: Alínea, 2009. p. 149-191.

BELLI, J. I. R; BITTENCOURT, E. A reprovação da titulação no ensino de engenharia.In: CONGRESSO BRASILEIRO DE ENSINO DE ENGENHARIA DE PRODUÇÃO: EMPREENDER E PRESERVAR, 34., 2006, Passo Fundo. Anais... Passo Fundo: Universidade do Estado de Santa Catarina, 2006. 
p. 2099-2105. Disponível em: <http://www.dee.ufma.br/ fsouza/anais/ arquivos/2_215_932.pdf>. Acesso em: 7 jun. 2008.

CAPITÃO, C. G; VILLEMOR-AMARAL, A. E. A pesquisa com estudo de caso. In: BAPTISTA, M. N.; CAMPOS, D. C. de. Metodologia de pesquisa em ciências: análises quantitativa e qualitativa. Rio de Janeiro: LTC, 2007. cap. 19, p. 238-253.

CHIZZOTTI, A. Metodologia do ensino superior: o ensino com pesquisa. In: CASTANHO, S.; CASTANHO, M. E. (Org.). Temas e textos em metodologia do ensino superior. Campinas: Papirus, 2001. cap. 8, p. 103-112.

FREIRE, P. Pedagogia da esperança: um reencontro com a pedagogia do oprimido. Rio de Janeiro: Paz e Terra, 1992.

GRILLO, M. 0 professor e a docência: o encontro com o aluno. In: ENRICONE, D. (Org.). Ser professor. 2. ed. Porto Alegre: Edipucrs, 2001. p. 73-89.

LODER, L. L. 0 bom professor de engenharia: visão dos alunos versus visão dos professores aproximações e distanciamentos. In: CONGRESSO BRASILEIRO DE ENSINO DE ENGENHARIA, 32., 2005, Campina Grande, PB. Anais... Campina Grande, 2005. Disponível em: <http://www.abenge.org.br/ CobengeAnteriores/2005/artigos/RS-15-22158499087-1118761250370.pdf>. Acesso em: 8 abr. 2009.

LORENZATO, S. Para aprender matemática. Campinas: Autores Associados, 2006.

MENEGAT, L. A. Relação entre compreensão leitora e aprendizagem matemática: uma investigação com licenciandos em matemática. 2007. 114 f. Dissertação (Mestrado em Educação em Ciências e Matemática) Pontifícia Universidade Católica do Rio Grande do Sul, Rio Grande do Sul, 2007.

PASSOS, F. G. et al. Diagnóstico sobre a reprovação nas disciplinas básicas dos cursos de engenharia da Univasf. In: CONGRESSO BRASILEIRO DE ENSINO DE ENGENHARIA, 35., 2007, Curitiba. Anais... Curitiba: ABENGE, 2007. p. 1-16.

PINTO, E. Avaliação de ingressantes. In: FELTRAN, R. C. de S. Avaliação na educação superior. Campinas: Papirus, 2002. cap 3, p. 83-108

RAMOS, M. O. et al. A reprovação por frequência nos cursos de engenharia da Universidade Federal do Vale do São Francisco: um olhar dos docentes e discentes. In: CONGRESSO BRASILEIRO DE ENSINO DE ENGENHARIA, 36., 2008, São Paulo. Anais... São Paulo: ABENGE, Escola Politécnica da Universidade de São Paulo, 2008. p. 1-13.1 CD-ROM. 
RIBEIRO, T. R. L. T et al. Fatores pedagógicos interferentes no processo de aprendizagem dos estudantes de engenharia da Univasf. In: CONGRESSO NORTE NORDESTE DE PSICOLOGIA, 7., 2011, Salvador. Anais... Salvador 2011. 1 CD-ROM.

SOUSA, G. M. C. et al. reprovação nas disciplinas básicas: uma reflexão dos aspectos pedagógicos na perspectiva dos docentes e discentes aprovados. In: CONGRESSO BRASILEIRO DE ENSINO DE ENGENHARIA, 39., 2011, Blumenau, SC. Anais... Blumenau, SC: ABENGE, Escola Politécnica da Universidade de São Paulo, 2011.

ROMANOWSKI, J. P. Aprender: uma ação interativa. In: VEIGA, I. P. A. (Orğ.). Lições de didática. Campinas: Papirus, 2006.

SILVA, L. P.; CECÍLIO, S. A mudança no modelo de ensino de formação na engenharia. Educação em Revista, Belo Horizonte, n. 45, p. 61-80, jun. 2007. Disponível em: <http://www.scielo.br/scielo.php?script=sci_arttext\&pid =S0102-46982007000100004>. Acesso em: 6 jul. 2011.

TACCA, M. C. V. R. Estratégias pedagógicas: conceituação e desdobramento com o foco nas relações professor-aluno. In: TACCA, M. C. V. R. (Org.). Aprendizagem e trabalho pedagógico. 2. ed. Campinas: Alínea, 2008. p. 45-68.

VILLAS BOAS, B. M. Avaliação no trabalho pedagógico universitário. In: CASTANHO, S. et al. (Org.). O que há de novo na educação superior: do projeto pedagógico à prática transformadora. Campinas: Papirus, 2000. 